\title{
Direitos humanos no contexto da Educação de Jovens e Adultos: contribuições das percepções de estudantes
}

Marciele Stiegler Ribas

Ana Maria Eyng

Romilda Teodora Ens

Pontifícia Universidade Católica do Paraná

\section{Resumo}

presente artigo analisa as percepções dos estudantes da Educação de Jovens e Adultos (EJA) sobre Direitos Humanos. A pesquisa, de abordagem qualitativa, contou com a participação de 198 estudantes de cinco Centros Estaduais de Educação Básica para Jovens e Adultos (CEEBJA's) situados no município de Curitiba-Paraná. Nos resultados identificamos denúncias de violações do direito à educação, quanto à precariedade das condições escolares. Os estudantes percebem como inadequados os materiais didáticos, a infraestrutura de suas escolas, e a existência de professores desqualificados, ao mesmo tempo que reivindicam seus direitos: à educação de qualidade, à igualdade, ao respeito, à diferença. Tanto as violações que identificam quanto as reivindicações de direitos, confirmam um cenário de tensões entre uma proposta de Educação em Direitos Humanos (EDH) e práticas escolares excludentes reiteradas. As percepções dos estudantes podem contribuir para a proposição de ações que minimizem as diversas formas de violação de direitos presentes no interior da escola, alertando para as vicissitudes da EJA.

Palavras-chave: Direitos humanos. Educação de Jovens e Adultos. Educação em direitos humanos.

\section{Human Rights in the context of adult and youth education: contribu- tions from the perceptions of students}

\section{Abstract}

This article examines the perceptions from students of Youth and Adult Education (EJA) on Human Rights. The research, on qualitative approach, was attended by 198 students from five State Elementary Education Centers for Youth and Adults (CEEBJA's) situated in the municipality of Curitiba-Paraná. The results identify complaints of violations of the right to education, as to the precariousness of the conditions. Students perceive as inadequate teaching materials, the infrastructure of their schools, unqualified teachers and, at the same time. Claim their rights: to education of quality, equality, respect, to 
Direitos humanos no contexto da Educação de Jovens e Adultos: contribuições das percepções de estudantes

difference. Both the violations they identify and the claims of rights, confirm a scenario of tensions between a proposal for Human Rights Education (EDH) and school exclusive repeated practices. The perceptions of students can contribute to the proposal of actions that minimize various forms of violation of rights present inside the school, alerting to the vicissitudes of the EJA.

Keywords: Human Rights. Adult and youth education. Human Rights Education.

\section{Derechos humanos en el contexto de la Educación de Jóvenes y Adultos: contribuciones de las percepciones de los estudiantes}

\section{Resumen}

Este artículo analiza las percepciones de los estudiantes de la Educación de Jóvenes y Adultos (EJA) sobre Derechos Humanos. La investigación, de enfoque cualitativo, tuvo la participación de 198 alumnos de cinco Centros Estatales de Educación Básica para Jóvenes y Adultos (CEEBJA's) ubicados en la ciudad de Curitiba, Paraná. En los resultados, identificamos quejas de violaciones del derecho a la educación, con relación a la precariedad de las condiciones escolares. Los estudiantes se dan cuenta de los materiales inadecuados de enseñanza, la infraestructura de sus escuelas, y la existencia de profesores no cualificados, mientras que ellos reivindican sus derechos: a la calidad de la educación, la igualdad, el respeto y a la diferencia. Ambas violaciones que se identifican como las reivindicaciones de derechos confirman un escenario de tensiones entre una propuesta para la Educación en Derechos Humanos (EDH) y las prácticas de exclusión de la escuela. Las percepciones de los estudiantes pueden contribuir a la proposición de medidas para reducir al mínimo las diversas formas de violación de los derechos presentes en la escuela, advirtiendo de las vicisitudes de la EJA.

Palabras clave: Derechos Humano. Educación de Jóvenes y Adultos. Educación en Derechos Humanos.

\section{Introdução}

tema "direitos humanos" ganha força nos anos 1990, com a promulgação da Constituição Federal (BRASIL, 1988), que, ao colocar em prática políticas sociais, possibilitou discussões nacionais que culminaram na aprovação de políticas que definem a inclusão dos direitos humanos no currículo escolar. Em especial, o Plano Nacional de Educação em Direitos Humanos 
(BRASIL, 2008) e as Diretrizes Curriculares para a Educação em Direitos Humanos (BRASIL, 2012) tratam dessa inclusão.

A Educação em Direitos Humanos se vincula ao direito à educação, mas ainda se observam violações de direitos no interior das escolas, entre elas a negação do próprio direito à educação. Assim, pensar sobre direitos humanos, hoje, implica refletir sobre sua efetivação no espaço/tempo da escola e da sociedade, pois, "[...] não se trata simplesmente de garantia de acesso e permanência na escola, mas da garantia de acesso, da permanência com qualidade e do sucesso na formação integral, considerando a diversidade de contextos e sujeitos" (EYNG, 2013, p. 31).

Essa premissa é válida para toda a educação básica, incluindo suas respectivas modalidades, no caso dessa reflexão, a Educação de Jovens e Adultos (EJA). A EJA, conforme art. 37 da Lei de Diretrizes e Bases da Educação Nacional (LDBN n. 9.394/1996) é uma modalidade da educação básica "[...] destinada àqueles que não tiveram acesso ou continuidade de estudos no ensino fundamental e médio na idade própria", ou seja, 15 anos para o ensino fundamental e 18 anos para o ensino médio (BRASIL, 1996). A história da EJA, segundo alusão de Arroyo (2006, p. 221 1), " [... ] se confunde com a história do lugar social reservado aos setores populares. É uma modalidade do trato dado pelas elites aos adultos populares".

Os estudantes que chegam à EJA podem ter sido vitimados por uma dupla violação de direitos que se inicia na falta da oferta de uma educação de qualidade social ${ }^{1}$ e culmina, em muitos casos, com a exclusão dos estudantes, tanto na escola, como da escola, propriamente dita. Nesse contexto, identificamos a contradição entre a garantia do direito à educação e a contribuição da escola para a reprodução das desigualdades sociais, conforme alerta Bourdieu (2013).

Assim, segundo alusão de Campos; Leal e Facci (2016, p. 2226): "No discurso, a escola é para todos, mas no cotidiano, o acesso ao conhecimento ainda acaba sendo destinado a uma parcela específica da população $[\ldots]^{\prime \prime}$, da qual os estudantes que recorrem à EJA não fizeram parte. Nessa modalidade de oferta da educação básica, costumeiramente, os estudantes voltam à escola, profundamente marcados pela desigualdade e pela exclusão, depois de terem sido evadidos, excluídos do ensino regular, ou mesmo, sem nunca o terem frequentado. Como consequência, carregam consigo, ainda 
Direitos humanos no contexto da Educação de Jovens e Adultos: contribuições das percepções de estudantes

que de forma inconsciente, marcas da exclusão e incapacidade, produzidas por uma sucessiva violação de direitos, em muitos casos, iniciada com a negação do direito à educação.

Quando retornam à escola, na modalidade da EJA, essa violação persiste, pois ainda é evidente "[...] a visão compensatória que atribui à educação de jovens e adultos a mera função de reposição de escolaridade não realizada na infância ou adolescência" (DI PIERRO, 2006, p. 20), por conseguinte, assente em uma visão estritamente certificadora.

Essa função compensatória, em certa medida, é reproduzida e reforçada pelo poder público, por exemplo, ao destinar para o financiamento da EJA apenas o montante de 15\% do Fundo de Manutenção e Desenvolvimento da Educação Básica e de Valorização dos Profissionais da Educação Fundeb, o qual substitui o Fundo de Manutenção e Desenvolvimento do Ensino Fundamental e de Valorização do Magistério - Fundef, sendo regulamentado pela Lei n. 11.494 , de 20 de junho de 2007 (BRASIL, 2007), compromete a possibilidade de configuração da identidade dessa modalidade de educação. Isso é confirmado por Haddad e Ximemes (2008, p. 146) ao afirmarem que a EJA é "[...] a única a contar com essa espécie de trava de expansão", 102 ratificando a posição da EJA no cenário das políticas públicas, sendo referidá pelos autores como "um direito de segunda categoria".

O baixo investimento, somado à secundarização da EJA em relação aos outros níveis e modalidades de ensino, resulta em diversos déficits educativos, como, por exemplo: infraestrutura inadequada, falta de formação específica para os professores atuarem nessa modalidade, descaracterização do seu público-alvo e de sua função, meramente compensatória. Essa descaracterização é evidente nas próprias Diretrizes Nacionais para a Educação de Jovens e Adultos (BRASIL, 2000) que, embora enfatizem as especificidades da EJA, direcionam a utilização das Diretrizes do ensino fundamental e médio² para essa modalidade. Com base nesse cenário, podemos dizer que tais deficiências no campo educacional evidenciam e reforçam a violação do direito à educação na EJA.

A violação de tal direito evidenciada nessa modalidade de ensino enfatiza um modelo de Estado, atuando como monopólio da classe dominante, cujos interesses não incluem as classes dominadas, das quais fazem parte os estudantes da EJA. Portanto, "Negar ou desconsiderar a luta desigual, 
travada por parcela significativa da população para conquistar direitos e diminuir a exploração" e, mais, "[...] apontar o Estado como bem de todos, trata-se de posição ingênua, idealista, que soma com a perspectiva da dominação" (CAMPOS; LEAL; FACCl, 2016 , p. 213).

Apesar da luta ser desigual, os direitos sociais, historicamente conquistados, resultam das reivindicações das classes populares por melhores condições de subsistência, como alimentação, saúde, trabalho, educação, entre outras. As conquistas provêm das lutas por reivindicações de garantia de direitos.

Nesse sentido, os questionamos, a seguir, são bastante pertinentes: Quais seriam as reivindicações por garantia de direitos dos estudantes da EJA? E os estudantes da EJA têm consciência da violação de seus direitos?

As respostas a essas questões exigem dar voz aos estudantes dessa modalidade de ensino. Com a preocupação de respondê-las, propusemos, nesta pesquisa, o questionamento seguinte: Quais as percepções de estudantes da Educação de Jovens e Adultos sobre direitos humanos?

As percepções em análise foram obtidas a partir de uma pesquisa de abordagem qualitativa, para a qual contribuíram 198 estudantes da EJA, matriculados em cinco Centros Estaduais de Educação Básica para Jovens e Adultos (CEEBJA's) do município de Curitiba-Paraná, que cursavam a etapa correspondente ao ensino médio.

A elucidação da problemática anunciada se referenda na reflexão sobre os direitos humanos no contexto da EJA, fundamentada, em Bourdieu (2013), Candau (201 1), Eyng (2013), Santos (2013), e outros.

\section{Percurso metodológico}

A pesquisa empírica, com base na técnica Delphi ${ }^{2}$, realizou-se em duas fases. Na primeira, foi levantado o perfil dos estudantes da EJA lidade, sexo, etnia e faixa de renda mensall, além da resposta escrita à questão: "O que você entende por direitos humanos na escola?", formulada com o intuito de identificar as percepções individuais dos estudantes sobre esses direitos. Após análise desse material, elaboramos um segundo instrumento, sob forma de escala de classificação, o qual compreende as categorias levantadas pelas 
Direitos humanos no contexto da Educação de Jovens e Adultos: contribuições das percepções de estudantes

respostas à questão inicialmente proposta, acompanhadas de suas respectivas frases explicativas, sobre os direitos humanos na escola (TABELA 5).

Para a elaboração do segundo instrumento de análise das percepções estudantis, foram seguidas as orientações de Lefevre e Lefevre (20 12 ), na análise do Discurso do Sujeito Coletivo (DSC), a qual consiste em interpretar as significações e as ideias centrais emergidas nas respostas dos participantes, agrupando ideias semelhantes em uma única categoria. Desse modo, "[...] a construção do Discurso do Sujeito Coletivo é feita com Expressões-chaves das Ideias Centrais enquadradas na mesma categoria" (LEVEFRE; LEVEFRE, 2012, p. 79).

Após a elaboração do instrumento, aplicado na segunda fase da pesquisa, retornamos aos CEEBJA's para coletar as respostas dos participantes da primeira fase. Nesse momento, foi proposto a esses estudantes que classificassem, individualmente, as frases/categorias de acordo com o grau de importância atribuído a cada uma delas, elegendo, em seguida, a mais importante para a efetivação dos direitos humanos na escola, justificando sua escolha.

Na segunda fase, cada estudante tem a possibilidade de refletir sobre todas as categorias, ponderando sobre sua resposta inicial e analisando os posicionamentos de outros estudantes ao eleger a percepção que considera a mais importante. "Dessa forma evita-se que haja influência e interferência entre os envolvidos, permitindo que todos se manifestem autêntica e livremente" (EYNG, 1995, p. 63).

\section{Traços identitários e percepções dos estudantes da EJA sobre direitos humanos na escola}

Anteriormente à análise das percepções dos estudantes da EJA sobre direitos humanos na escola, apresentamos os traços identitários dos participantes em relação à idade, sexo, etnia e faixa de renda mensal, respectivamente (Tabelas 1, 2, 3 e 4). 


\section{Tabela 1}

Idade dos estudantes da EJA

$\begin{array}{cc}\text { ldade } & \% \\ 18 \text { e } 22 \text { anos } & 36 \\ 23 \text { e } 27 \text { anos } & 20 \\ 38 \text { e } 43 \text { anos } & 11 \\ 44 \text { e } 48 \text { anos } & 6 \\ 49 \text { e } 53 \text { anos } & 4 \\ 54 \text { e } 58 \text { anos } & 2 \\ 59 \text { anos ou mais } & 2 \\ \text { Não respondeu } & 1\end{array}$

Fonte | Dados da pesquisa empírica (2015).

Utilizando como parâmetro o disposto no Estatuto da Juventude, Lei $n^{\circ}$ 12.852, de 5 de agosto de 2013, que define como jovens as pessoas entre 15 e 29 anos de idade, na Tabela 1 observamos a confirmação da inserção de estudantes cada vez mais jovens na EJA (BRASIL, 2013). Esse dado é apontado por Brunel (2004) como uma característica dessa modalidade a partir dos anos 1990, em decorrência da aprovação da Lei de Diretrizes e Bases da Educação Nacional - LDBN n 9.394, de 20 de dezembro de 1996, a qual determina, para a EJA, artigo 38, que a idade mínima para ingresso no ensino fundamental seja 15 anos e 18 anos para o ensino médio (BRASIL, 1996). 0 aumento de jovens ingressantes, na etapa correspondente ao ensino médio nessa modalidade, com idade entre 18 e 29 anos converge com os resultados do Censo Escolar de 2013, no qual a média nacional de estudantes matriculados nessa modalidade é de 28 anos de idade (INEP, 2014).

A presença significativa da parcela cada vez mais jovem na educação de jovens e adultos, como evidenciada na faixa etária dos participantes da pesquisa (Tabela 1), nos instiga a questionar uma faceta concernente à ampliação da exclusão oriunda do ensino regular: qual a causa da evasão desses estudantes? Em decorrência disso, estaria a EJA sendo configurada como uma modalidade de ensino para a mera correção de fluxo e não como espaço público de garantia do direito à educação? Talvez o problema maior encontre-se no círculo vicioso originado desde o ensino regular, no qual, uma vez excluídos, os alunos (nem todos), são direcionados para a EJA. Nela, os que permanecem, em sua maioria, não têm acesso ao ensino superior, 
Direitos humanos no contexto da Educação de Jovens e Adultos: contribuições das percepções de estudantes

reproduzindo-se assim, mais uma vez, a exclusão a que foram submetidos desde o ensino regular. Tal exclusão acaba gerando um contrassenso na própria escola, denominado por Bourdieu e Champagne de "paradoxo mentiroso", pois, nele, os estudantes:

Obrigados pelas sanções negativas da escola a renunciar às aspirações escolares e sociais que a própria escola lhes havia inspirado, e, em suma, forçados a diminuir suas pretensões, levam adiante, sem convicção, uma escolaridade que sabem não ter futuro (BOURDIEU; CHAMPAGNE, 2013, p. 251)

Outro indicador social preocupante refere-se aos jovens de 15 a 29 anos de idade que não trabalham, não estudam e não procuram emprego, cognominados, na linguagem popular, principalmente pela mídia de "nem, nem, nem". De acordo com os dados do IBGE (2015), esse contingente representa 13,9\% do total de jovens nesta faixa etária, perfazendo um total de 6,8 milhões de pessoas, sendo que a média de estudos desses jovens é de 8,3 anos, ou seja, representam possíveis demandas para a modalidade da EJA.

Em relação ao sexo dos participantes da pesquisa (Tabela 2), o per-

106 centual entre homens e mulheres está equilibrado (52\% do sexo feminino e 47\% do masculino).

\section{Tabela 2}

\section{Sexo dos estudantes da EJA}

$\begin{array}{cc}\text { Sexo } & \% \\ \text { Feminino } & 52 \\ \text { Masculino } & 47 \\ \text { Não respondeu } & 1\end{array}$

Fonte | Dados da pesquisa empírica (2015).

Já no que diz respeito à etnia (Tabela 3), 64\% dos participantes se autodeclararam branca, $25 \%$ parda e $5 \%$ negra. 


\section{Tabela 3}

Etnia dos estudantes da EJA

$\begin{array}{cc}\text { Etnia } & \% \\ \text { Branco } & 64 \\ \text { Pardo } & 25 \\ \text { Negro } & 5 \\ \text { Não respondeu } & 5\end{array}$

Fonte | Dados da pesquisa empírica (2015).

A faixa de renda mensal desses estudantes (Tabela 4) varia entre menos de um salário mínimo e mais de cinco salários mínimos ${ }^{4}$. A maioria (54\%) tem como renda mensal de um a dois salários mínimos. Em seguida, com $18 \%$, temos os que recebem de dois a três salários mínimos. O percentual daqueles que recebem menos de um salário mínimo corresponde a $9 \%$ dos participantes.

\section{Tabela 4}

\section{Renda mensal dos estudantes da EJA}

Renda mensal
Menos de um salário mínimo
De 1 a 2 salários mínimos
De 2 a 3 salários mínimos
De 3 a 4 salários mínimos
De 4 a 5 salários mínimos
Mais de 5 salários mínimos
Não respondeu
Fonte | Dados da pesquisa empírica (2015).

Os traços identitários desses estudantes demonstram que eles são predominantemente pobres, brancos, mulheres, com idade entre 18 e 27 anos.

Em relação às percepções dos estudantes sobre direitos humanos na escola, ao compararmos os dados obtidos nas duas fases da pesquisa, foi possível identificar uma diferença da primeira para a segunda fase. Na primeira etapa quando os estudantes responderam, individualmente, à questão "O que você entende por direitos humanos na escola?", as percepções mais indicadas foram: "direito ao respeito" (23\%), "direito à educação de qualidade" (19\%) e 
"direito ao estudo" (19\%). Na segunda etapa, a qual envolveu a aplicação do segundo instrumento, originado das respostas categorizadas da primeira fase, compreendendo categorias, acompanhadas de suas respectivas frases explicativas, extraídas do agrupamento das ideias similares dos respondentes (TABELA 51 , as categorias mais indicadas foram: "direito à educação de qualidade" (34,3\%), "direito à igualdade" (15,8\%) e "direito ao estudo" (15, 1\%).

\section{Tabela 5}

Direitos humanos na escola: percepções de estudantes da EJA

Categorias

Direito à educação de qualidade

Direito à igualdade

Direito ao estudo

Direito ao respeito

Direito à diversidade

Direito à liberdade de expressão

Direito ao diálogo

Cumprimento de regras e normas

Não responderam Frase explicativa (DSC)

Direitos humanos na escola é a garantia de uma educa-

\% Estudantes

$34,3 \%$

$15,8 \%$

$15,1 \%$

Direitos humanos na escola é a garantia do direito ao estudo; independente da idade, todos têm o direito de concluir o ensino médio para melhorar a sua condição profissional, ou mesmo, ingressar no mercado de trabalho.

Direitos humanos na escola é o respeito mútuo entre professores, estudantes e funcionários.

Direitos humanos na escola é a garantia do respeito à diversidade em relação à idade, etnia, opção sexual, classe social e crença.

Direitos humanos na escola é o direito de se expressar $4,8 \%$ expondo ideias, opiniões e questionamentos.

Direitos humanos na escola é a garantia do diálogo $4,1 \%$ entre aluno e professor para a maior participação dos estudantes.

Direitos humanos na escola é o cumprimento de regras e $3,4 \%$ normas presentes nas leis para uma boa conduta.

Fonte | Dados da pesquisa empírica (2015). 
Concernente à primeira categoria, "direito à educação de qualidade", é importante assinalar que, conforme alude Silva (2009, p. 223) "[...] a qualidade social da educação não se restringe a fórmulas matemáticas, tampouco a resultados estabelecidos a priori e a medidas lineares descontextualizadas".

Evidenciamos, nos depoimentos dos estudantes (Tabela 5), a denúncia pertinente a, pelo menos, quatro fatores a serem observados para a efetivação de uma educação de qualidade social no contexto da EJA: infraestrutura e material adequado; boa alimentação; segurança e qualificação dos professores.

Em relação à infraestrutura, o Estudante 28 (2015) denuncia: "[...] nós temos o direito e merecemos um espaço melhor e salas melhores, pois trabalhamos o dia todo e deixamos a família para vir para a escola para um futuro melhor pra nós e para o Brasil".

Quanto ao material inadequado, o Estudante 52 (2015) indica: "[... ] temos pouca estrutura e pouco material". A falta de segurança no período noturno também ficou evidente, "[...] o que falta muito é a segurança nas escolas, estamos à mercê da criminalidade" (ESTUDANTE 67, 2015). A alimentação insuficiente é retratada na resposta do Estudante 32 (2015): "[...] todos merecem ter uma boa educação e merenda". Sendo reiterada pelo Estudante 103 (2015): "Uma boa alimentação faz uma diferença e tanto".

Esse cenário é consequência do baixo investimento nessa modalidade por parte dos entes federados. Conforme denunciam Haddad e Di Pierro (2000, p. 124): "Consolidaram-se a tendência à descentralização do financiamento e dos serviços, bem como a posição marginal ocupada pela educação básica de jovens e adultos nas prioridades de política educacional".

Essa posição marginal da EJA acaba, também, sendo refletida na formação específica de professores para atuar nessa modalidade de ensino. Alguns estudantes reivindicam professores mais qualificados: "É preciso mais investimento na educação e qualificação dos professores" (ESTUDANTE 43, 2015): "Professores qualificados fazem muito bem porque assim eles sabem como lidar com jovens dessa época" (ESTUDANTE 103, 2015).

Diversas pesquisas comprovam que a formação de professores para atuar na EJA, acontece no desenvolvimento da prática pedagógica do professor e não nas licenciaturas, os quais trazem "[...] em sua prática as marcas da precarização e, embora a despeito da sua criatividade e compromisso, têm 
Direitos humanos no contexto da Educação de Jovens e Adultos: contribuições das percepções de estudantes

sua docência constituída na improvisação e no aligeiramento" (CAPUCHO, 2012 , p. 65).

Assim, o docente que atua na EJA se depara com várias dificuldades provenientes da falta, ou mesmo, insuficiente formação, pois algumas licenciaturas ofertam a disciplina de EJA, mas com carga horária muito reduzida.

Nas políticas de formação de professores, bem como nas políticas educacionais direcionadas à EJA, observa-se a ausência de indicativos que contemplem uma proposta de formação específica para atuar nessa modalidade de ensino. Entre as percepções verificadas com os estudantes da EJA para o alcance da qualidade social na educação, as mais urgentes seriam, no mínimo: "[...] ampliar o financiamento destinado à EJA e rever a situação de despreparo e desvalorização profissional dos educadores que a ela se dedicam" (DI PIERRO, 2010, p. 954).

Diante das denúncias e reivindicações dos estudantes, constatadas nesta pesquisa conceituamos a qualidade da educação a partir da proposição de Silva (2009, p. 225): "A escola de qualidade social é aquela que [...] luta por financiamento adequado, pelo reconhecimento social e valorização dos trabalhadores em educação [...]", e ainda, se propõe a transformar "[...] todos os espaços físicos em lugar de aprendizagens significativas e de vivências efetivamente democráticas".

Nessa perspectiva, a oferta de uma educação de qualidade social passa, também, pela questão da oferta da Educação em Direitos Humanos, na qual os "[...] direitos individuais, coletivos e transindividuais, considerando a igualdade e a diferença, necessitam de processos educativos formais e informais para que sejam apreendidos, vivenciados e protegidos" (EYNG, 2013, p. 311 .

A segunda categoria, referente ao "direito à igualdade", assim hierarquizada por 15,8\% dos estudantes, apresenta como reivindicação um tratamento igualitário para todos: "Direito à igualdade, pois todas as pessoas têm o direito de serem tratadas igualmente" (ESTUDANTE 108, 2015); "Todos têm que ter o mesmo tratamento, sem discriminação" (ESTUDANTE 144, 2015 ).

Ao se reportarem à discriminação, denotam a necessidade de a escola considerar as diferenças individuais. Essa constatação fica evidente na categoria relativa ao "direito à diversidade": "Todos merecem respeito, não importa a função, a idade" (ESTUDANTE 76, 2015). A questão da idade foi 
apontada várias vezes pelos alunos. Como uma característica peculiar da EJA, esta não pode ser ignorada, mas considerada em conjunto com os demais traços identitários dos estudantes que caracterizam a diversidade nela presente, como, por exemplo, "[...] opção sexual, classe social e crença" (ESTUDANTE 135, 2015). Acrescentamos, ainda, a diversidade cultural. Um fator que nos chama a atenção é a conotação negativa dada pelos participantes ao se reportarem "às diversidades", uma vez que apareceram acompanhadas da discriminação, afinal sempre são citadas com o adendo "independente" da opção sexual, etnia, etc.

A diversidade, característica evidente na EJA, enriquece ainda mais as múltiplas possibilidades educativas nessa modalidade. Entretanto, as diferenças aparecem com uma acepção negativa, e não o contrário. Tal significação negativa é resultado da lógica da padronização presente na escola, imposta, segundo argumentação de Candau (2011, p. 241), pela "cultura escolar dominante", a qual "[...] prioriza o comum, o uniforme, o homogêneo, considerados como elementos constitutivos do universal. Nessa ótica, as diferenças são ignoradas ou consideradas um 'problema' a resolver". Essa constatação reforça a necessidade de se trabalhar tais diferenças de forma positiva, o que implica, ainda nas palavras de Candau (201 1, p. 253): "[...] a promoção de dispositivos de diferenciação pedagógica e o combate a toda forma de preconceito e discriminação no contexto escolar".

Tais dispositivos educativos necessitam de ações e políticas educacionais que respeitem a diversidade cada vez mais proeminente na educação. Assim, conteúdos de direitos humanos poderão contribuir para uma formação direcionada à cidadania se estiverem pautados em uma perspectiva da globalização contra-hegemônica, conceituada por Santos (2013, p. 9) como "globalização a partir de baixo", sendo constituída "[...] pelos movimentos e organizações sociais que, mediante articulações locais, nacionais e globais, lutam contra a opressão capitalista e colonialista [...]". Essa opressão, argumenta o autor, gera

[...] a desigualdade e a discriminação racial e sexual, a destruição dos modos de vida de populações empobrecidas, a catástrofe ecológica e a expulsão de camponeses e povos indígenas dos seus territórios ancestrais, o endividamento das famílias, dos pequenos empresários e dos Estados como forma de controle social e político, a criminalização do protesto social (SANTOS, 2013, p. 9). 
Direitos humanos no contexto da Educação de Jovens e Adultos: contribuições das percepções de estudantes

Tal posicionamento pressupõe uma Educação em Direitos Humanos em uma perspectiva intercultural na qual se busca "[...] promover uma educação para o reconhecimento do 'outro', para o diálogo entre os diferentes grupos sociais e culturais [...]" (CANDAU, 2008, p. 52, grifo da autora).

Na terceira categoria "direito ao estudo", os estudantes da EJA fazem referência ao trabalho. Segundo depoimento do Estudante 49 (2015), o direito ao estudo é fundamental "Para melhorar os conhecimentos e conquistar um trabalho digno e em consequência uma qualidade de vida melhor a seus familiares". A questão do trabalho no contexto da EJA é essencial para "compreender como se estabelecem, na prática, as relações entre o sistema de ensino e o aparelho econômico [...]" (BOURDIEU; BOLTANSKI, 2013, p. 150 e 146). Nas palavras dos autores: "[...] a escola tende a ocupar um lugar cada vez mais importante na medida em que o aparelho econômico se desenvolve e ganha uma complexidade cada vez maior". Como consequência, as pessoas buscam ou são levadas a procurar maior escolarização para a obtenção de diplomas.

Primeiramente, precisamos considerar que o público da EJA possui uma condição econômica precária; afinal, faz parte de uma classe social 112 desfavorecida. Por esse motivo, esses jovens e adultos, em sua maioria, foram obrigados a abandonar os estudos para trabalhar, como forma de sobrevivência, o que evidencia mais uma forma de exclusão social. Diante do crescimento econômico para se manterem empregados ou "empregáveis", voltam à escola em busca de melhor qualificação para o mercado de trabalho. Contudo, conforme denuncia Bourdieu (20 13, p. 45), o sistema escolar não é "[...] um fator de mobilidade social" e, adverte: "[...] tudo tende a mostrar que ele é um dos fatores mais eficazes de conservação social, pois fornece a aparência de ligitimidade às desigualdades sociais, e sanciona a herança cultural e o dom social tratado como dom natural".

Por considerarmos que a inserção social dos estudantes da EJA não pode ser mensurada, apenas, pelo acesso à educação, ou pela obtenção de um diploma do ensino médio e tendo em vista a exigência cada vez maior de qualificação para o mercado de trabalho, questionamos: Quais as chances reais de esses estudantes, desprovidos de um capital cultural ${ }^{5}$, ingressarem em uma universidade? 
Assim, [...] em virtude da lentidão do processo de aculturação, [as] diferenças sutis ligadas às antiguidades do acesso à cultura continuam a separar indivíduos aparentemente iguais quanto ao êxito social e mesmo ao êxito escolar. A nobreza cultural também tem seus graus de descendências (BOURDIEU, 2013, p. 47, grifo nosso).

Na quarta categoria, o respeito foi mencionado pelos estudantes desta pesquisa, como fundamental para a efetivação dos direitos humanos na escola, constituindo a categoria: "direito ao respeito", que assim justificaram:

Todos merecem respeito ninguém é melhor do que ninguém, se a gente está aqui é para estudar e não para ser desrespeitado (ESTUDANTE 138, 2015).

Direito ao respeito mútuo (ESTUDANTE 139, 2015).

Todos os alunos devem respeitar os professores, funcionários, através deles seguimos em frente, concluindo os estudos e conseguindo empregos melhores (ESTUDANTE 146, 2015).

Assim, como base na dimensão essencial no processo educativo. Sobretudo no contexto da EJA, ele precisa ser mais vivenciado, pois está atrelado às categorias discutidas anteriormente: "direito à educação de qualidade"; "direito ao estudo"; "direito à igualdade" e "direito à diferença". Respeitar os estudantes da EJA significa ofertar a eles uma educação de qualidade social, a qual oportunize a igualdade de direitos, bem como o respeito e o reconhecimento das suas diferenças individuais e coletivas. Quanto ao respeito, Freire destaca ainda:

[...] saber que devo respeito à autonomia, à dignidade e à identidade do educando e, na prática procurar a coerência com esse saber, me leva inapelavelmente à criação de algumas virtudes ou qualidades sem as quais aquele saber vira inautêntico, palavreado vazio e inoperante (FREIRE, 2003, p. 62).

respeito acarreta outra implicação, evidenciada na categoria "direito ao diálogo". Entre as argumentações dos estudantes para a escolha dessa categoria como a mais importante, a explicitada com maior frequência foi a da necessidade de diálogo entre professor e aluno: "Precisamos dialogar com nossos professores e eles também com a gente" (ESTUDANTE 124, 2015). 
Direitos humanos no contexto da Educação de Jovens e Adultos: contribuições das percepções de estudantes

O diálogo, como alerta Freire (1992, p. 18), tem um significado importante na ação pedagógica, "[...] precisamente, porque os sujeitos dialógicos não apenas conservam sua identidade, mas a defendem e assim crescem um com o outro. $\bigcirc$ diálogo por isso mesmo nivela, não reduz um ao outro".

Postulam a necessidade do diálogo como também o desejo de liberdade de expressão: "Todos têm o direito de se expressar" (ESTUDANTE 34, 2015); "[...] tem ideias, opiniões e questionamentos que podem ser discutidos com a maioria e ser resolvido em benefício de todos" (ESTUDANTE 58, 2015). Tanto na categoria "direito ao diálogo" quanto na "direito à liberdade de expressão", parece-nos que os estudantes reivindicam um maior protagonismo na escola. Tal constatação, de certa forma, converge com um dos princípios da Educação em Direitos Humanos: a democracia na educação.

\section{Considerações...}

Neste trabalho, refletimos sobre os direitos humanos no contexto da Educação de Jovens e Adultos, reafirmamos a violação de direitos sofrida por

114 essa parcela da população, integrante da classe dominada. Evidenciamos suas carências educativas, decorrentes do baixo investimento do Estado somado à secundarização dessa modalidade. Buscamos dar voz aos seus estudantes.

Para tanto, a partir da abordagem qualitativa, com a utilização da técnica Delphi, realizamos uma pesquisa empírica com o público da EJA, comumente excluído dos processos escolares. Nosso objetivo consistiu em analisar as percepções desses estudantes sobre os direitos humanos. As percepções mais enfatizadas foram: direito à educação de qualidade; direito à igualdade; direito ao estudo; direito ao respeito; direito à diversidade; direito à liberdade de expressão e direito ao diálogo.

Os participantes da pesquisa denunciaram a precariedade da educação ofertada na EJA em relação à infraestrutura, ao material didático que consideram inadequado, à alimentação, à segurança e à qualificação dos professores. Reivindicaram um tratamento igualitário frente à diversidade de idade, opção sexual e religião, manifestando a importância do respeito. Salientaram o direito ao estudo, independentemente da idade, visando à melhoria das condições econômicas. Mencionaram, ainda, a necessidade de um maior protagonismo na escola por meio do diálogo e da liberdade de expressão. 
Essas percepções sobre direitos humanos na escola, as quais podem ser traduzidas em denúncias e reivindicações, confirmam o pressuposto, inicialmente levantado neste artigo, de que a escola além de contribuir para a reprodução das desigualdades sociais, também reproduz a violação do direito à educação no interior da própria escola. Com efeito, tais percepções constituem-se em fontes que podem auxiliar na minimização dessas violações, bem como alertam para as vicissitudes da EJA.

Tratando-se de uma modalidade de ensino que carrega consigo as marcas da exclusão social e da violação de direitos, nos parece urgente que seja incluída a Educação em Direitos Humanos no currículo da EJA. Nesse sentido, uma educação de qualidade social nessa modalidade instiga a conscientização dos seus estudantes sobre direitos individuais e coletivos.

As denúncias de violações e as reivindicações constatadas reforçam a relevância e importância da EDH no contexto dessa modalidade de ensino. Essa argumentação fica acentuada nos princípios estabelecidos pelas Diretrizes da Educação em Direitos Humanos (BRASIL, 2012) que se pautam na dignidade humana. Quando voltamos nosso olhar para a EJA, em especial para os seus estudantes, entendemos quão imperativo é garantir a dignidade humana, via educação.

\section{Notas}

1 Sendo compreendida "como uma prática social e um ato político" (SILVA, 2009, p. 217), a educação de qualidade social é aquela que, além dos aspectos operacionais como infraestrutura adequada, material didático, professores qualificados, promove uma educação política com vistas à emancipação.

2 De acordo com o "Art. $3^{\circ}$ - As Diretrizes Nacionais do Ensino Fundamental estabelecidas e vigentes na Resolução CNE/CEB 2/98 se estendem para a modalidade da Educação de Jovens e Adultos no ensino fundamental" e, conforme o "art. $4^{\circ}$ - As Diretrizes Nacionais do Ensino Médio estabelecidas e vigentes na Resolução CNE/CEB 3/98 se estendem para a modalidade da Educação de Jovens e Adultos no ensino médio" (BRASIL, 2000).

3 Como explica Antunes (2014, p. 64) inicialmente "[...] se aplica um questionário, com características exploratórias, montado de forma a colher informações preliminares que serão analisadas, definindo o primeiro round. A partir dos questionários respondidos e analisados no primeiro round, gera-se um segundo questionário, que retorna para que os informantes originais respondam as novas questões, constituindo assim o segundo round [... $]^{\prime \prime}$.

$4 \bigcirc$ valor do salário mínimo, durante a realização da pesquisa empirica (2015), perfazia o total de $R \$ 788,00$. 
Direitos humanos no contexto da Educação de Jovens e Adultos: contribuições das percepções de estudantes

5 "Para Bourdieu, o capital cultural constitui o elemento da herança familiar que teria o maior impacto na definição do destino escolar. Seria uma espécie de rentabilização pedagógica, na medida em que a posse do capital cultural favorece o desempenho escolar, uma vez que facilita a aprendizagem de conteúdos e códigos que a escola veicula e sanciona" (CUNHA, 2007, p. 515).

\section{Referências}

ANTUNES, Marcelo Moreira. Técnica Delphi: metodologia para pesquisas em educação no Brasil. Revista de Educação, Campinas, v. 19, n. 1, p. 63-71, jan./abr. 2014.

ARROYO, Miguel Gonzales. A educação de jovens e adultos em tempos de exclusão. In: UNESCO. Construção coletiva: contribuições à educação de jovens e adultos. Brasília: UNESCO/MEC/RAAAB, 2006.

BOURDIEU, Pierre. A escola conservadora: as desigualdades frente à escola e à cultura. Tradução Aparecida Joly Gouveia. In: NOGUEIRA, Maria Alice; CATANI, Afrânio. Escritos de educação. 14. ed. Petrópolis: Vozes, 2013.

BOURDIEU, Pierre; CHAMPAGNE, Patrick. Os excluídos do interior. Tradução Magali de Castro. In: NOGUEIRA, Maria Alice; CATANI, Afrânio. Escritos de educação. 14. ed. 116 Petrópolis: Vozes, 2013.

BOURDIEU, Pierre; BOLTANSKI, Luc. O diploma e o cargo: relações entre o sistema de produção e o sistema de reprodução. Tradução Magali de Castro. In: NOGUEIRA, Maria Alice; CATANI, Afrânio. Escritos de educação. 14. ed. Petrópolis: Vozes, 2013.

BRASIL. Lei $\mathbf{n}^{\circ} \mathbf{1 2 . 8 5 2}$, de 5 de agosto de 2013. Institui o Estatuto da Juventude e dispõe sobre os direitos dos jovens, os princípios e diretrizes das políticas públicas de juventude e - Sistema Nacional de Juventude - SINAJUVE. Disponível em: http://www.planalto.gov.br/ ccivil_03/_Ato2011-2014/2013/Lei/L12852.htm. Acesso em: 8 maio 2016.

Ministério da Educação. Conselho Nacional de Educação. Conselho Pleno. Resolução $\mathbf{n}^{\circ}$ 1, de $\mathbf{3 0}$ de maio de 2012. Diretrizes Nacionais para a Educação em Direitos Humanos. Disponível em: http://rl.ufrri.br/wp/cpa/wp-content/uploads/file/CPA/ rcp00 1_12_Direitos_humanos.pdf. Acesso em: 6 jan. 2015.

Comitê Nacional de Educação em Direitos Humanos. Plano Nacional de Educação

em Direitos Humanos. Brasília: Secretaria Especial dos Direitos Humanos, Ministério da Educação, Ministério da Justiça, UNESCO, 2008. Disponível em: http://portal.mi.gov.br/ sedh/edh/pnedhpor.pdf. Acesso em: 20 mar. 2015. 
Resolução CNE/CEB n 1, de 5 de julho de 2000. Estabelece as Diretrizes Curriculares Nacionais para a Educação e Jovens e Adultos. Diário Oficial [da] União, Poder Executivo, Brasília, DF, 19 jul. 2000. Seção 1, p. 18.

Lei $\mathbf{n}^{\circ}$ 9.394, de 20 de dezembro de 1996. Estabelece as diretrizes e bases da educação nacional. Disponível em: <http://www.planalto.gov.br/ccivil_03/Leis/L9394. htm>. Acesso em: 15 jan. 2013.

Constituição da República Federativa do Brasil. Texto promulgado em 5 de outubro de 1988. Brasília: Senado Federal: Secretaria Especial de Editoração e Publicações: Subsecretaria de Edições Técnicas, 2010. Disponível em: <http://www.senado.gov.br/ legislacao/const/con 1988/CON1988_05.10.1988/CON1988.pdf>. Acesso em: 10 jan.2012.

BRUNEL, Carmem. Jovens cada vez mais jovens na educação de jovens e adultos. Porto Alegre: Mediação, 2004.

CAMPOS, Herculano Ricardo; LEAL, Záira Fátima de Rezende Gonzalez; FACCl, Marilda Gonçalves Dias. Direito à educação, formação do adolescente e adoecimento docente no Estado capitalista. Revista Educação em Questão, Natal, v. 54, n. 40, p. 205-230, jan.-abr. 2016. Disponível em: <https://periodicos.ufrn.br/educacaoemquestao/article/ view/9854/6982>. Acesso em: 04 jan. 2017.

CANDAU, Vera Maria. Diferenças culturais, cotidiano escolar e práticas pedagógicas. Currículo sem Fronteiras, v. 11 , n. 2, p. 240-255, jul./dez. 2011.

Direitos humanos, educação e interculturalidade: as tensões entre igualdade e diferença. Revista Brasileira de Educação, Rio de Janeiro, v. 13, n. 37, p. 45-56, jan./abr. 2008.

CAPUCHO, Vera. Educação de jovens e adultos: prática pedagógica e fortalecimento da cidadania. São Paulo: Cortez, 2012.

CUNHA, Maria Amália de Almeida. $\bigcirc$ conceito "capital cultural" em Pierre Bourdieu e a herança etnográfica. Perspectiva, Florianópolis, v. 25, n. 2, p. 503-524, jul./dez. 2007.

DI PIERRO, Maria Clara. Um balanço da evolução recente da educação de jovens e adultos no Brasil. In: UNESCO. Construção coletiva: contribuições à educação de jovens e adultos. Brasília: UNESCO/MEC/RAAAB, 2006.

- A educação de jovens e adultos no Plano Nacional de Educação: avaliação, desafios e perspectivas. Educação \& Sociedade, Campinas, v. 31 , n. 1 12, p. 939-959, jul.-set. 
2010. Disponivel em: http://dx.doi.org/10.1590/S0101-73302010000300015. Acesso em: 24 mai. 2012.

ESTUDANTE 28. Entrevista. Curitiba (Paraná), 25 jun. 2015.

ESTUDANTE 32. Entrevista. Curitiba (Paraná), 25 jun. 2015.

ESTUDANTE 34. Entrevista. Curitiba (Paraná), 25 jun. 2015.

ESTUDANTE 43. Entrevista. Curitiba (Paraná), 30 jun. 2015.

ESTUDANTE 49. Entrevista. Curitiba (Paraná), 30 jun. 2015.

ESTUDANTE 52. Entrevista. Curitiba (Paraná), 30 jun. 2015.

ESTUDANTE 58. Entrevista. Curitiba (Paraná), 22 jun. 2015.

ESTUDANTE 67. Entrevista. Curitiba (Paraná), 22 jun. 2015.

ESTUDANTE 76. Entrevista. Curitiba (Paraná), 22 jun. 2015.

ESTUDANTE 103. Entrevista. Curitiba (Paraná), 3 jul. 2015.

ESTUDANTE 108. Entrevista. Curitiba (Paraná), 24 jun. 2015.

ESTUDANTE 124. Entrevista. Curitiba (Paraná), 19 jun. 2015.

ESTUDANTE 135. Entrevista. Curitiba (Paraná), 19 jun. 2015.

ESTUDANTE 138. Entrevista. Curitiba (Paraná), 6 jul. 2015.

ESTUDANTE 139. Entrevista. Curitiba (Paraná), 6 jul. 2015.

ESTUDANTE 144. Entrevista. Curitiba (Paraná), 6 jul. 2015.

ESTUDANTE 146. Entrevista. Curitiba (Paraná), 6 jul. 2015.

EYNG, Ana Maria. Educação em Direitos Humanos no currículo escolar: o projeto políitico pedagógico como espaço de garantia ou violação de direitos. In: EYNG, Ana Maria (Org.). Direitos Humanos e violências nas escolas: desafios e questões em diálogo. Curitiba: Editora CRV, 2013 . p. 29-58.

A formação do homem no processo pedagógico e sua fundamentação antropofilosófica: um estudo de caso. Dissertação (Mestrado em Educação), Curitiba, 1995. (Mimeo). 
FREIRE, Paulo. Pedagogia da autonomia: saberes necessários à prática educativa. 24. ed. São Paulo: Paz e Terra, 2003.

Pedagogia da Esperança. Rio de Janeiro: Paz e Terra, 1992.

HADDAD, Sérgio; DI PIERRO, Maria Clara. Escolarização de Jovens e Adultos. Revista Brasileira de Educação, Rio de Janeiro, v. 13, n. 37, p. 108-1 30, maio/ago. 2000. Disponível em: http: / / educa.fcc.org.br/scielo.php?.pid=S 141 3-24782000000200007\&script=sci_ abstract. Acesso em: 9 abr. 2013.

HADDAD, Sérgio; XIMENES, Salomão. A educação de pessoas jovens e adultas e a nova LDB: um olhar passado dez anos. In: BRZEZINSKI, Iria. (Org.). LDB dez anos depois: reinterpretação sob diversos olhares. São Paulo: Cortez, 2008.

IBGE. Pesquisa Nacional por Amostra de Domicílios. Dados do IBGE de 2014, considerando todas as faixas etárias. Disponível em: http://www.ibge.gov.br/home/. Acesso em: 3 mar. 2015.

Síntese dos indicadores sociais: uma análise das condições de vida da população brasileira, 2015. Disponível em: <http://biblioteca.ibge.gov.br/visualizacao/livros/ liv95011.pdf> Acesso em: 18. abr. 2016.

INEP. Censo escolar da educação básica 2013: resumo técnico. Instituto Nacional de Estudos e Pesquisas Educacionais Anísio Teixeira. Brasília: INEP, 2014.

LEVEFRE, Fernando; LEVEFRE, Ana Maria. Pesquisa de representação social: um enfoque qualiquantitativo a metodologia do discurso do sujeito coletivo. 2. ed. Brasília: Liber Livro Editora, 2012.

SANTOS, Boaventura de Souza. Se Deus fosse um ativista dos direitos humanos. São Paulo: Cortez, 2013.

SILVA, Maria Abadia. Qualidade social da educação pública: algumas aproximações. Cadernos Cedes, Campinas, v. 29, n. 78, p. 21 6-226, maio/ago. 2009.

Doutoranda Marciele Stiegler Ribas Pontifícia Universidade Católica Programa de Pós-Graduação em Educação Grupo de Pesquisa Políticas Públicas e Formação de Professores 
Grupo de Pesquisa Políticas, Formação de Professores, Trabalho Docente e Representações Sociais Bolsista CAPES/Fundação Araucária E-mail | marci.stiegler.ribas@gmail.com

Profa. Dra. Ana Maria Eyng Pontifícia Universidade Católica do Paraná Programa de Pós-Graduação em Educação Coordenadora do Observatório de Violências nas Escolas Coordenadora Institucional do PIBID/PUCPR Líder do Grupo de Pesquisa Políticas Públicas e Formação de Professores E-mail | eyng.anamaria@gmail.com Profa. Dra. Romilda Teodora Ens Pontifícia Universidade Católica do Paraná Programa de Pós-Graduação em Educação Pesquisadora Associada da Fundação Carlos Chagas Líder do Grupo de Pesquisa Políticas, Formação de Professores, Trabalho Docente e Representações Sociais | POFORS Integra a Cádetra da UNESCO sobre Profissionalização Docente E-mail | romilda.ens@gmail.com

Recebido 2 jun. 2016 Aceito 6 dez. 2016 